\title{
Evaluation on the potential of betaine, taurine, nucleotide and nucleoside as feeding stimulant for juvenile marble goby Oxyeleotris marmoratus through behavioural assays
}

\author{
Leong-Seng Lim • Sian-Kang Jason Lai • Annita Seok-Kian Yong • \\ Rossita Shapawi · Gunzo Kawamura
}

Received: 29 November 2015/ Accepted: 28 March 2016/Published online: 25 April 2016

(C) The Author(s) 2016. This article is published with open access at Springerlink.com

\begin{abstract}
This study was conducted to evaluate the potential of betaine, taurine, inosine (INO), inosine $5^{\prime}$ monophosphate disodium (IMP. $\left.\mathrm{Na}_{2}\right)$, and guanosine $5^{\prime}$-monophosphate disodium $\left(\mathrm{GMP} \cdot \mathrm{Na}_{2}\right)$ as a feeding stimulant for juvenile marble goby (Oxyeleotris marmoratus) (total length $6.6-8.5 \mathrm{~cm}$ ) through behavioural assays using agar gel pellets. All fish were conditioned to accept agar gel pellet before the behavioural assays started. Each chemical substance was tested on 50 replicates of individual fish once, and the overall ingestion rate was calculated as the representative data. The pure agar gel pellet was totally rejected by the fish $(0 \%$ ingestion rate). Therefore, any added test substance which can significantly improve the fish ingestion of the agar gel pellet can be the potential feeding stimulant. Of all the chemical substances tested at $0.1 \mathrm{M}$ concentration, the ingestion rates of both INO and IMP. $\mathrm{Na}_{2}$ were the highest (both $100 \%$ ) and were significantly higher $(P<0.05)$ than those of the other chemical substances tested. However, INO was identified as the most potent feeding stimulant as it could function perfectly $(100 \%)$ even at the lower concentrations tested $(0.01$ and $0.001 \mathrm{M})$. The ingestion rates of IMP. $\mathrm{Na}_{2}$ were found significantly decreased $(P<0.05)$ at the concentrations of 0.01 and $0.001 \mathrm{M}$ (78 and $2 \%$, respectively). The ingestion rate of GMP. $\mathrm{Na}_{2}$ at $0.1 \mathrm{M}$ was $60 \%$, hence higher concentration $(>0.1 \mathrm{M})$ may be required to improve its efficiency as the feeding stimulant. Taurine was not a feeding stimulant, and betaine was neither a feeding stimulant nor feed enhancer for the juvenile $O$. marmoratus.
\end{abstract}

Keywords Feeding stimulant $\cdot$ Nucleotides and nucleosides $\cdot$ Betaine $\cdot$ Marble goby $\cdot$ Oxyeleotris marmoratus $\cdot$ Behaviour

Abbreviations
$\begin{array}{ll}\text { INO } & \text { Inosine } \\ \text { IMP·Na } & \text { Inosine } 5^{\prime} \text {-monophosphate disodium } \\ \text { GMP·Na } & \text { Guanosine } 5^{\prime} \text {-monophosphate disodium } \\ \text { FS } & \text { Feeding stimulant } \\ \text { FT pellet } & \text { For-training pellet } \\ \text { PAG pellet } & \text { Pure agar gel pellet } \\ \text { TS pellet } & \text { Test substance pellet } \\ \text { AAM } & \text { Amino acids mixture } \\ \text { CI } & \text { Confidence interval }\end{array}$

L.-S. Lim $(\varangle)$ · S.-K. J. Lai · A. S.-K. Yong · R. Shapawi · G. Kawamura Borneo Marine Research Institute, Universiti Malaysia Sabah, Jalan UMS, 88400 Kota Kinabalu, Sabah, Malaysia e-mail: leongsen@ums.edu.my 


\section{Introduction}

Feeding stimulant (FS) is defined as the substance which has high ingestion rate by fish (Kasumyan and Døving 2003). In aquaculture, dietary supplementation of FS has been commonly practised to pellet-wean (Person-Le Ruyet 1989; Kubitza and Lovshin 1999; Hirt-Chabbert et al. 2012) and improve the feed intake in fish (Dias et al. 1997; Xue and Cui 2001; Papatryphon and Soares 2000). However, the taste preference in fish is species-specific (Kasumyan and Døving 2003); therefore, the effective FS should be identified prior to the dietary supplementation. Betaine, taurine, nucleotides and nucleosides are amongst the commonly known FS for fish (Kasumyan and Døving 2003; Chatzifotis et al. 2008; Lech and Reigh 2012). In addition, betaine is also known to be a potential feed enhancer for fish, which itself contains no effect of taste stimulant, but it can enhance the flavour of other chemical substances in a mixture (Kasumyan and Døving 2003).

Marble goby (Oxyeleotris marmoratus) is a high commercial value fish species in the aquaculture industry in many Southeast Asian countries, including Thailand, Malaysia, Singapore, Vietnam, and China for mass production (Tan and Lam 1973; Tavarutmaneegul and Lin 1988; Cheah et al. 1994; Luong et al. 2005; Wang et al. 2011). However, there is a feeding problem in the culture of O. marmoratus at grow-out stage. The feeding practise for this fish has been continuously relying on the low value fish (Bundit and Jauncey 2008) or live fish, which can easily deteriorate the quality of the rearing water and subsequently cause disease outbreak (Lam et al. 2008; 2014). Such feeding practise has been continued because there has been lack of commercial pelleted feeds for O. marmoratus (Cheah et al. 1994; Lin and Kaewpaitoon 2000), and this fish generally rejected pelleted feeds (Rojtinnakorn et al. 2012). Successful weaning generally requires long period of time, and cause high fish mortality due to starvation. Although FS can be applied to wean $O$. marmoratus to accept pelleted feeds, information on the suitable FS for this species is limited. In our previous study, amino acids mixture appeared to be more efficient than single amino acid as FS for the juvenile O. marmoratus when determined through behavioural assays (Lim et al. 2015). Apart from this, no study has been conducted to evaluate the effectiveness of other potential FS including betaine, taurine, nucleotide and nucleoside on $O$. marmoratus. Therefore, this study was conducted to investigate the possibility of using betaine, taurine, nucleotide and nucleoside as feeding stimulants for juvenile $O$. marmoratus.

Table 1 Types of agar gel pellet with its ingredients and composition prepared in the present study

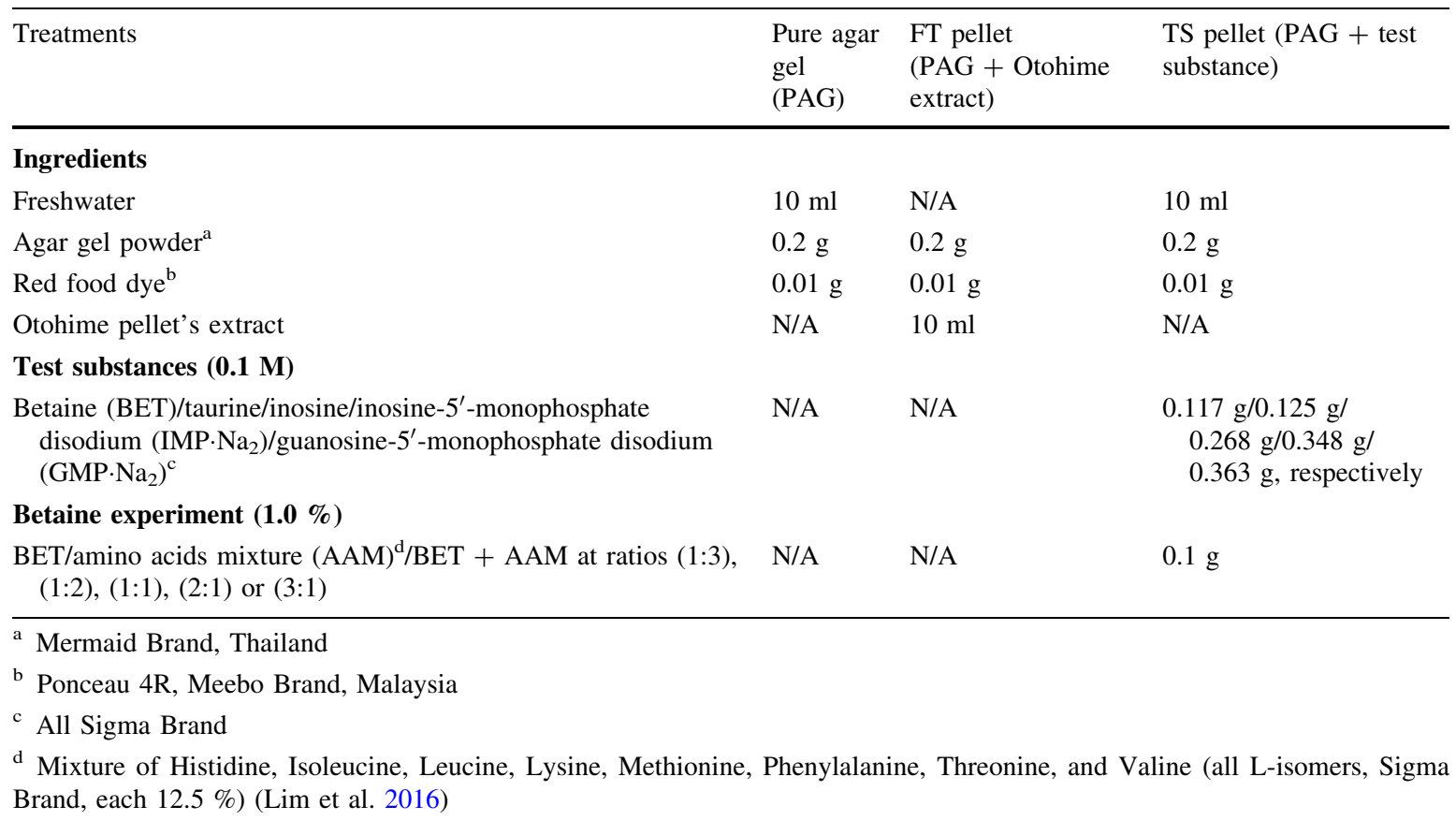




\section{Methods}

Preparation of agar gel pellets

The ingredients, composition and type of the agar gel pellets prepared and used in this study are shown in Table 1. The method of preparing agar gel pellets was similar to those described in Lim et al. (2015). In general, agar gel pellets were prepared by dissolving the agar gel powder ( $2 \%$ of the freshwater volume) and red food dye $(0.1 \%)$ in $10 \mathrm{ml}$ freshwater, boiled the mixture in a microwave oven, poured the boiled mixture into a glass petri dish for hardening, and subsequently cut it into uniform size (approximately $3 \mathrm{~mm} \times 3 \mathrm{~mm} \times 3 \mathrm{~mm}$ ) of pellet. Three major types of agar gel pellet were prepared in this study, namely the FT (for-training) pellet, the PAG (pure agar gel) pellet, and the TS (test substance) pellet (refer Table 1 for the content). The FT pellet was used to condition the fish to accept agar gel pellet; the PAG pellet (without inclusion of any test substance) was served as the negative control, while the TS pellets contained each test substance, which was betaine, taurine, inosine-INO (nucleoside), inosine-5'-monophosphate disodiumIMP. $\mathrm{Na}_{2}$ or guanosine- $5^{\prime}$-monophosphate disodium- $\mathrm{GMP} \cdot \mathrm{Na}_{2}$ (nucleotides).

In FT pellet, the water extract of the commercial marine finfish pellet (Otohime Brand, EP type, Japan, crude protein and crude lipid levels are 48 and $12 \%$, respectively) was used to replace the freshwater. The water extract of the Otohime commercial pellet was prepared by soaking the pellet powder $(5 \mathrm{~g})$ in $50 \mathrm{ml}$ of freshwater with occasional stirring for about 20 min until the water was turned into dark brown colour, then filtered the homogenate through a $60 \mu \mathrm{m}$ mesh net to obtain the liquid (extract). All extracts were freshly attained prior to the FT pellets preparation. For the TS pellets, $0.1 \mathrm{M}$ of betaine, taurine, INO, IMP. $\mathrm{Na}_{2}$ or GMP. $\mathrm{Na}_{2}$ was dissolved into the boiled mixture of agar gel powder, food dye and freshwater before the mixture was poured into the glass petri dish for hardening. For the test substances which were highly preferred by the fish, they were tested on the fish with lower concentrations $(0.01$ and $0.001 \mathrm{M})$ to determine their threshold for promoting the fish ingestion.

Another set (seven types) of agar gel pellets was prepared with the method modified from Lim et al. (2016) to test the taste effect of betaine as a feed enhancer. These agar gel pellets contained $1 \%$ of betaine, amino acids mixture (AAM) or different rates of betaine + AAM as shown in Table 1. The preparation method for these agar gel pellets were similar to the preparation of the TS pellets as described above. All prepared agar gel pellets were stored in a refrigerator $\left(4^{\circ} \mathrm{C}\right)$ for not more than four days to maintain their freshness.

\section{Experimental fish}

Fifty tails of juvenile marble goby (O. marmoratus) (total length $6.6-8.8 \mathrm{~cm}$ ) were obtained from the fish hatchery of Borneo Marine Research Institute (BMRI). The fish were first acclimatised in a $40 \mathrm{~L}$ glass aquarium in the indoor wet laboratory of BMRI, supplied with aeration. The fish were adapted to feed Otohime commercial marine finfish pellet. Otohime is well-known for its fine quality, and it is commonly used to culture high commercial value of carnivorous marine fish, such as groupers. Tank cleaning was done, and about $50 \%$ water in the aquarium was exchanged daily. After all fish were successfully adapted to feed on the Otohime commercial pellet in about 30 days, each fish were transferred to a transparent $3 \mathrm{~L}$ acrylic aquarium with $1 \mathrm{~L}$ water and aeration supply. Subsequently, these fish were conditioned to accept agar gel pellet.

\section{Fish conditioning}

Before the behavioural assays started, the fish were individually conditioned to accept agar gel pellet using the FT pellet. The conditioning method was similar with that described by Lim et al. (2015). All fish were firstly starved for $24 \mathrm{~h}$, and three pieces of FT pellet were given to the fish daily. Those fish which accepted the given FT pellets were subsequently rewarded with a few pieces of Otohime commercial pellet. On the other hand, no Otohime commercial pellet was given to those fish which rejected or did not show any response to the FT pellets. These fish were starved and the conditioning continued the next day. The fish were considered ready for the behavioural assays only when they consumed all the FT pellets in the continuous three days of training. In this study, all fish (50 individuals) were successfully trained to accept the FT pellets after 11 days of conditioning. No fish mortality was observed throughout the conditioning period. 
Behavioural assays

The behavioural assays started after all fish were successfully conditioned to accept agar gel pellet. Each treatment of TS pellet was fed to 50 replicates of the individual fish. The procedure of the behavioural assays in this study was adopted from that of Kasumyan and Morsi (1996) with modifications. The behavioural assays began by providing a piece of FT pellet to the fish to trigger its feeding desire, followed with a TS pellet, and then another piece of FT pellet. The last piece of FT pellet was served to recover the fish acceptance to agar gel pellet because the fish may be conditioned to reject agar gel pellet if any of the chemical substances tested was a deterrent to the fish. During the behavioural assays, the feeding responses of each fish to the given TS pellet (ingested or rejected) were observed and recorded. If the fish did not show any response to the given TS pellet (the TS pellet was not captured in mouth by the fish), that particular assay was not counted, and it will be repeated the other day. Each TS pellet was tried only once on each fish to avoid adaptation of the fish to the chemical substance tested, and only one test to the fish in each day. The PAG pellet was used as the negative control in the behavioural assay, and it was tested on the fish as the other TS pellets were. After each of the successful assay, the fish was rewarded with the Otohime commercial pellet until apparent satiation level. Tank cleaning was conducted and about $50 \%$ of water in each aquarium was exchanged in the next day at least $4 \mathrm{~h}$ before the behavioural assays started. Throughout the experimental period, the water temperature in aquarium ranged from 28 to $29^{\circ} \mathrm{C}$.

Data collection and analysis

In this study, the feeding response of juvenile $O$. marmoratus to each treatment of agar gel pellet was observed for 50 replicates. As the feeding response observed was a binary data (ingested or rejected the TS pellet), binomial test was used for the data statistical analysis. The total ingestion rate for each treatment of agar gel pellet was calculated using the formula "A/B $\times 100 \%$ " where A represented the total ingestion observed, while B represented the total replicates (50), and its $95 \%$ confidence interval (CI) was calculated following the Clopper-Pearson exact method (Clopper and Pearson 1934). The range of the $95 \%$ CI of agar gel pellet treatment was compared to each other; if the ranges of $95 \%$ CI between two agar gel treatments were not overlapped, significant difference was assumed and vice versa (Sauro and Lewis 2012).

\section{Results and discussion}

This is the first report on the feeding response of juvenile $O$. marmoratus to betaine, taurine, inosine (INO), inosine-5'-monophosphate disodium (IMP. $\left.\mathrm{Na}_{2}\right)$, and guanosine-5'-monophosphate disodium $(\mathrm{GMP} \cdot \mathrm{Na} 2)$. In this study, the pure agar gel pellet (PAG) was totally rejected by the fish, hence its ingestion rate was $0 \%$.

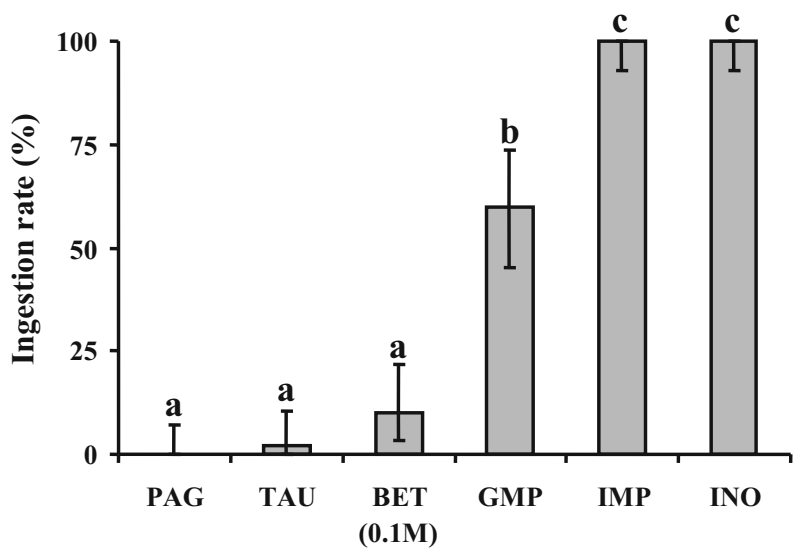

Fig. 1 Ingestion rates of the juvenile $O$. marmoratus on different treatments of TS pellet with the test substance concentration level at $0.1 \mathrm{M}$ 
Therefore, any added test substance which was able to significantly improve the fish ingestion rate on the agar gel pellet can be considered as the potential feeding stimulant (Lim et al. 2015; 2016). Figure 1 shows the ingestion rates of the juvenile $O$. marmoratus on different treatments of TS pellet. Among the 5 chemical substances tested in $0.1 \mathrm{M}$ concentration, the ingestion rates of betaine $(5 \%)$ and taurine $(2 \%)$ were very poor and showed no significant difference $(P>0.05)$ with that of the PAG. The ingestion rate of GMP.Na was moderately high $(60 \%)$ and significantly higher $(P<0.05)$ than those of PAG, betaine, and taurine. However, the ingestion rates of INO and IMP. Na 2 were perfected $(100 \%)$ as all replicates of fish ingested the INO and IMP.Na $\mathrm{NS}_{2}$ TS pellets, and these values were significantly higher $(P<0.05)$ than those of the other TS pellet treatments (PAG, betaine, taurine, and GMP. $\mathrm{Na}_{2}$ ). These results showed that INO and IMP.Na 2 were the most potential feeding stimulants for juvenile $O$. marmoratus although the application of higher concentration $(>0.1 \mathrm{M})$ of GMP. $\mathrm{Na}_{2}$ may improve the fish ingestion. Indeed, both IMP and INO were also reported as the feeding stimulant for several fish species, including turbot Scophthalmus maximus (Mackie and Adron 1978), brill Scophthalmus rhombus (Mackie and Mitchell 1985), and rainbow trout Salmo gairdneri (Mearns et al. 1987), but they were not to Atlantic salmon parr Salmo salar (Mearns et al. 1987) and tiger puffer Takifugu pardalis although they were identified to stimulate the taste buds on the lips of $T$. pardalis through electrophysiological recording (Hidaka et al. 1978). In other reports for yellowtail Seriola quinqueradiata (Takeda 1980), jack mackerel Trachurus japonicus (Ikeda et al. 1988; 1991) and largemouth bass Micropterus salmoides (Kubitza et al. 1997), IMP- $\mathrm{Na}_{2}$ or IMP was an effective feeding stimulant, but INO was not. Apparently, the feeding responses of fishes to nucleotides and nucleosides are species-specific as suggested by $\mathrm{Li}$ and Gatlin III (2006).

Considering the highest ingestion rate of INO and IMP $\cdot \mathrm{Na}_{2}$ in the juvenile O. marmoratus, these chemical substances were further tested on the fish with the lower concentrations (0.01 and $0.001 \mathrm{M})$ to detect their threshold to the fish. Figure 2 shows the fish ingestion rates of TS pellets with different concentrations of INO and IMP. $\mathrm{Na}_{2}$. The ingestion rates of IMP. $\mathrm{Na}_{2}$ at 0.001 and $0.01 \mathrm{M}$ were 2 and $78 \%$, respectively; these values were significantly lower $(P<0.05)$ than that of the $0.1 \mathrm{M} \mathrm{IMP-Na} 2(100 \%)$. On the other hand, the ingestion rates of INO at 0.001 and $0.01 \mathrm{M}$ were all $100 \%$, similar with that of the $0.1 \mathrm{M}$ INO. These results suggested that INO was more effective or suitable than IMP. $\mathrm{Na}_{2}$ to be used as a feeding stimulant for juvenile $O$. marmoratus in term of their functional dosage. Such results were in agreement with those reported on the marbled rockfish Sebasticus marmoratus by Takaoka et al. (1990).

Betaine is commonly known to possess synergistic effects with other chemical substances, especially amino acids; hence it can be a feed enhancer to some fish species (Kasumyan and Døving 2003). In this study, betaine was neither a feeding stimulant nor a feed enhancer to the juvenile O. marmoratus. Figure 3 shows the ingestion rates of the fish to the agar gel pellets with betaine, amino acids mixture (AAM) or betaine + AAM at different rates. Inclusion of betaine to the AAM did not improve the ingestion rates of the TS pellets despite changes in the ration of betaine and AAM. Such results were in contrast with those reported on brown-marbled grouper Epinephelus fuscoguttatus, where the ingestion rate of the agar gel pellet significantly $(P<0.05)$ increased after the inclusion of betaine to the AAM, even in a small portion (Lim et al. 2016). Indeed, betaine was also rejected by $S$. salar as reported by Mearns et al. (1987) through behavioural assays.

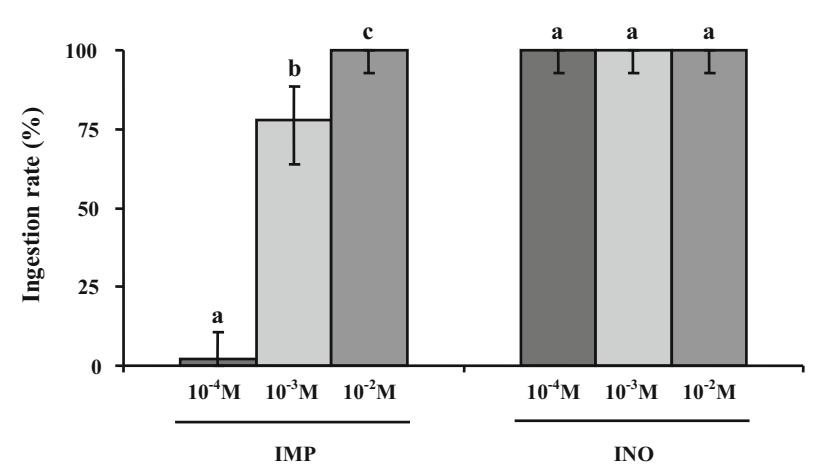

Fig. 2 Ingestion rate of the juvenile $O$. marmoratus on the TS pellets with inosine (INO) or inosine $5^{\prime}$-monophosphate disodium (IMP. $\mathrm{Na}_{2}$ ) at different concentration levels 


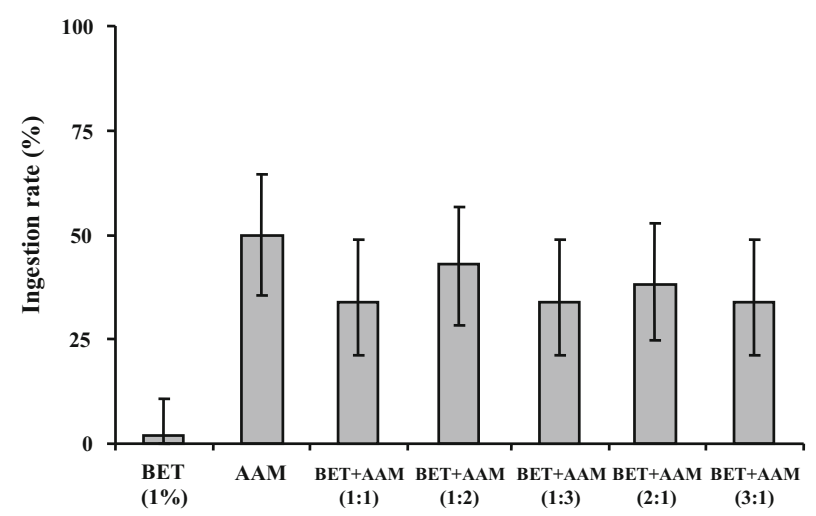

Fig. 3 Ingestion rate of the juvenile $O$. marmoratus on the TS pellets with $1 \%$ betaine, amino acids mixture (AAM) or different rates of betaine + AAM

\section{Conclusions}

In conclusion, INO was the most potent feeding stimulant for the juvenile O. marmoratus as it was still effective to promote fish ingestion even at low concentration $0.001 \mathrm{M}$. IMP $\cdot \mathrm{Na}_{2}$ was an effective feeding stimulant for the fish only at the concentration level of at least $0.1 \mathrm{M}$. Higher concentration of GMP. $\mathrm{Na}_{2}$ $(>0.1 \mathrm{M})$ may be required to improve its efficiency as the feeding stimulant. Taurine was not a feeding stimulant, and betaine was neither a feeding stimulant nor feed enhancer to the juvenile $O$. marmoratus. Further study should be conducted to evaluate the effectiveness of dietary INO supplementation to improve the pellet-weaning progress of juvenile $O$. marmoratus.

Acknowledgments This study was funded by the Fundamental Research Grant Scheme (Project code: FRG0399-STWN-2/ 2014) from the Ministry of Education of Malaysia.

Author contribution statement Leong-Seng Lim contributed the original idea of this study, designed the experimental methods and wrote the manuscript. Sian-Kang Jason Lai provided ideas to refine the experimental methods, conducted the experiments, collected and analysed the data. Annita Seok-Kian Yong and Rossita Shapawi provided ideas to refine the experimental methods and proof-read the manuscript. Gunzo Kawamura involved in designing the experimental methods, statistical analysis and proofread the manuscript.

\section{Compliance with ethical standards}

Conflict of interest No competing interests.

Open Access This article is distributed under the terms of the Creative Commons Attribution 4.0 International License (http:// creativecommons.org/licenses/by/4.0/), which permits unrestricted use, distribution, and reproduction in any medium, provided you give appropriate credit to the original author(s) and the source, provide a link to the Creative Commons license, and indicate if changes were made.

\section{References}

Bundit J, Jauncey K (2008) Farm-made feeds and their importance through using supplemental vitamin E, its effects on fish growth performance, biochemical composition and haematology of marble goby Oxyeleotris marmoratus. In: Proceedings in International Symposium on Sustaining Fish Diversity, Fisheries and Aquacultures in the Mekong Basin, Ubon Ratchathani, September 2008. Faculty of Agriculture, Ubon Ratchathani University, pp 1-7

Chatzifotis S, Polemitou I, Divanach P, Antonopoulou E (2008) Effect of dietary taurine supplement on growth performance and bile salt activated lipase activity of common dentex, Dentex dentex, fed a fish meal/soy protein concentrate-based diet. Aquaculture 275:201-208

Cheah SH, Senoo S, Lam SY, Ang KJ (1994) Aquaculture of a high-value freshwater fish in Malaysia: the marble or sand goby (Oxyeleotris marmoratus, Bleeker). Naga ICLARM Q 17:22-25

Clopper C, Pearson ES (1934) The use of confidence or fiducial limits illustrated in the case of the binomial. Biometrika 26:404-413 
Dias J, Gomes EF, Kaushik SJ (1997) Improvement of feed intake through supplementation with an attractant mix in European seabass fed plant-protein rich diets. Aquat Living Resour 10:385-389

Hidaka I, Ohsugi T, Kubomatsu T (1978) Taste receptor stimulation and feeding behaviour in the puffer, Fugu pardalis I. Effect of single chemicals. Chem Sense Flavour 3:341-354

Hirt-Chabbert JA, Skalli A, Young OA, Gisbert E (2012) Effects of feeding stimulants on the feed consumption, growth and survival at glass eel and elver stages in the European eel (Anguilla Anguilla). Aquac Nutr 18:152-166

Ikeda I, Hosokawa H, Shimeno S, Takeda M (1988) Identification of feeding stimulant in the krill extract for jack mackerel. Nippon Suisan Gakkaishi 54:235-238 (in Japanese with English abstract)

Ikeda I, Hosokawa H, Shimeno S, Takeda M (1991) Feeding stimulant activity of nucleotides, tryptophan, and their related compounds for jack mackerel. Nippon Suisan Gakkaishi 57:1539-1542 (in Japanese with English abstract)

Kasumyan AO, Døving KB (2003) Taste preferences in fish. Fish Fish 4:289-347

Kasumyan AO, Morsi AMKh (1996) Taste sensitivity of common carp Cyprinus carpio to free amino acids and classical taste substances. J Ichthyol 36:391-403

Kubitza F, Lovshin LL (1999) Formulated diets, feeding strategies, and cannibalism control during intensive culture of juvenile carnivorous fishes. Rev Fish Sci 7:1-22

Kubitza F, Lovshin LL, Lovell RT (1997) Identification of feed enhancers for juvenile largemouth bass Micropterus salmoides. Aquaculture 148:191-200

Lam SS, Ambak MA, Jusoh A, Law AT (2008) Waste excretion of marble goby (Oxyeleotris marmorata Bleeker) fed with different diets. Aquaculture 274:49-56

Lam SS, Ma NL, Jusoh A, Ambak MA (2014) A study on the optimal tank design and feed type to the growth of marble goby (Oxyeleotris marmoratus Bleeker) and reduction of waste in a recirculating aquaponic system. Desalin Water Treat 52:1044-1053

Lech GP, Reigh RC (2012) Plant products affect growth and digestive efficiency of cultured Florida Pompano (Trachinotus carolinus) fed compounded diets. PLoS One 7:e34981

Li P, Gatlin DM III (2006) Nucleotide nutrition in fish: current knowledge and future applications. Aquaculture 251:141-152

Lim LS, Lai JSK, Yong ASK, Shapawi R, Kawamura G (2015) A preliminary study on the taste preferences of marble goby (Oxyeleotris marmoratus) for amino acids. Songklanakarin J Sci Technol 37:397-400

Lim LS, Chor WK, Tuzan AD, Shapawi R, Kawamura G (2016) Betaine is a feed enhancer for juvenile grouper (Epinephelus fuscoguttatus) as determined behaviourally. J Appl Anim Res 44:415-418

Lin CK, Kaewpaitoon K (2000) An overview of freshwater cage culture in Thailand. In: Liao IC, Lin CK (eds) Proceedings of the First International Symposium on Cage Aquaculture in Asia, May 2000. Asian Fisheries Society, Manila, Philippine, pp 253-257

Luong VC, Yi Y, Lin CK (2005) Cove culture of marble goby (Oxyeleotris marmorata Bleeker) and carps in Tri An reservoir of Vietnam. Aquaculture 244:97-107

Mackie AM, Adron JW (1978) Identification of inosine and inosine 5'-monophosphate as the gustatory feeding stimulants for the turbot, Scophthalmus maximus. Comp Biochem Physiol A 60:79-83

Mackie AM, Mitchell AI (1985) Identification of gustatory feeding stimulants for fish—applications in aquaculture. In: Cowey CB, Mackie AM, Bell JG (eds) Nutrition and Feeding in Fish. Academic Press, London, pp 177-189

Mearns KJ, Ellingsen OF, Døving KB, Helmer S (1987) Feeding behaviour in adult rainbow trout and Atlantic salmon parr, elicited by chemical fractions and mixtures of compounds identified in shrimp extract. Aquaculture 64:47-63

Papatryphon E, Soares JHJ (2000) The effect of dietary feeding stimulants on growth performance of striped bass, Morone saxatilis, fed a plant feed stuff-based diet. Aquaculture 185:329-338

Person-Le Ruyet J (1989) Early weaning of marine fish larvae onto microdiets: constraints and perspectives. AQUACOP IFREMER Actes de Colloque 9:625-642

Rojtinnakorn J, Rittiplang S, Tongsiri S, Chaibu P (2012) Tumeric extract inducing growth biomarker in sand goby (Oxyeleotris marmoratus). In: Proceedings of the 2nd International Conference on Chemical, Biological and Environment Sciences (ICCEBS 2012), Bali, June-July, 2012. Planetary Scientific Research Centre, pp 41-43

Sauro J, Lewis JR (2012) Quantifying the user experience: practical statistics for user research. Morgan Kaufmann (MK) Publishers, Boston

Takaoka O, Takii K, Nakamura M, Kumai H, Takeda M (1990) Identification of feeding stimulants for marbled rockfish. Nippon Suisan Gakkaishi 56:345-351 (in Japanese with English abstract)

Takeda M (1980) Feeding stimulants for fish. Iden (Heredity) 34:45-51 (in Japanese)

Tan KK, Lam TJ (1973) Induced breeding and early development of the marble goby (Oxyeleotris marmorata, Blk.). Aquaculture 2:411-423

Tavarutmaneegul P, Lin K (1988) Breeding and rearing of sand goby (Oxyeleotris marmoratus Blk.) fry. Aquaculture 69:299-305

Wang Q, Zeng WW, Li KB, Cheng OQ, Liu C, Wu GH, Shi CB, Wu SQ (2011) Outbreaks of an Iridovirus in marbled sleepy goby Oxyeleotris marmoratus (Bleeker), cultured in southern China. J Fish Dis 34:399-402

Xue M, Cui Y (2001) Effect of several feeding stimulants on diet preference by juvenile gibel carp (Carassius auratus gibelio), fed diets with or without partial replacement of fish meal by meat and bone meal. Aquaculture 198:281-292 